\title{
Resilience and Adaptability for a Post-Pandemic World: Exploring Technology to Enhance Environmental Sustainability
}

Nofrijon Sofyan ${ }^{1}$, Akhmad Herman Yuwono ${ }^{1}$, Sri Harjanto ${ }^{1}$, Muhammad Arif Budiyanto ${ }^{2}$, Yudan Wulanza ${ }^{2}$, Nandy Putra ${ }^{2}$, Sutrasno Kartohardjono ${ }^{3}$, Eny Kusrini ${ }^{3}$, Mohammed Ali Berawi $^{3}$, Nyoman Suwartha ${ }^{3}$, Imam Jauhari Maknun ${ }^{3}$, Yandi Andri Yatmo ${ }^{4}$, Paramita Atmodiwirjo ${ }^{4}$, Muhamad Asvial ${ }^{5}$, Ruki Harwahyu ${ }^{5}$, Muhammad Suryanegara ${ }^{5}$, Eko Adhi Setiawan ${ }^{5}$, Teuku Yuri M. Zagloel ${ }^{6}$, Isti Surjandari 6

${ }^{1}$ Department of Metallurgy and Materials Engineering, Faculty of Engineering, Universitas Indonesia, Kampus UI Depok, Depok 16424, Indonesia

${ }^{2}$ Department of Mechanical Engineering, Faculty of Engineering, Universitas Indonesia, Kampus UI Depok, Depok 16424, Indonesia

${ }^{3}$ Department of Chemical Engineering, Faculty of Engineering, Universitas Indonesia, Kampus UI Depok 16424, Indonesia

${ }^{4}$ Department of Civil and Environmental Engineering, Faculty of Engineering, Universitas Indonesia, Kampus UI Depok, Depok 16424, Indonesia

${ }^{5}$ Department of Architecture, Faculty of Engineering, Universitas Indonesia, Kampus UI Depok, Depok 16424, Indonesia

${ }^{6}$ Department of Electrical Engineering, Faculty of Engineering, Universitas Indonesia, Kampus UI Depok, Depok 16424, Indonesia

${ }^{7}$ Department of Industrial Engineering, Faculty of Engineering, Universitas Indonesia, Kampus UI Depok, Depok 16424, Indonesia

The COVID-19 pandemic is still affecting many aspects of human life. Many efforts have been carried out by many parties in the fields of health and demographics, food security, secure and clean water, green and efficient energy sources, climate change, quality education and secure communities. The response of many scientists and technologists during this pandemic have successfully facilitated progress in many areas, such as effective vaccines to prevent further spreading of the pandemic and medical devices needed by many patients affected by COVID-19. In another domain, the policy responses of governments to the COVID-19 crisis have demonstrated that many major economies are capable of unprecedented and drastic action when it is called for.

Responding to these many challenges requires engagement, specifically in the research domain, at any level, locally and globally. The 17th International Conference on Quality in Research (QiR) 2021 was held to address these issues. Due to the global pandemic situation, the QiR 2021 was held online. Presenting the theme of "Resilience and Adaptability for a Post-Pandemic World: Exploring Technology for Our Green Environment," the QiR 2021 brought many research papers discussing the role of the science and technology during the pandemic. In this edition of the International Journal of Technology, we are proudly presenting 20 articles selected from the QiR 2021 and make them available to readers worldwide by highlighting research and development in various fields during the COVID-19 
pandemic.

In the first paper, Y. Rahayu, Rosdiansyah, M.F. Hilmi, and T. Odih discuss wearable antenna for time-domain breast tumor detection. In this research article, the authors focused on breast cancer, which is one of the major causes of the increased death rate among women. If this cancer can be detected early through periodic screenings, the chances of recovery from breast cancer can be improved. This work presented the development of a novel wearable and flexible multiple input multiple output (MIMO) $2 \times 4$ antenna design, which operates at a frequency of $5.5-7 \mathrm{GHz}$ for time-domain breast tumor detection. In the design, all antennas are located at the cup of the bra, which is divided into four quadrants and each quadrant has two antennas for tumor detection. Their results demonstrated that the antennas work well for tumor detection.

With the aim to develop an efficient thermoelectric power generator (TEG), the second paper written by M.A.S.M. Roseny, S. Sathiyamoorthy, M.F.M. Sabri, S.M. Said, P. Veluswamy, and F. Salleh discusses theoretical power output of thermoelectric power generator based on metal oxide semiconductor. The authors claimed that since the increase of electricity demand has caused major environmental issues such as resource depletion, pollution, and climate change due to the use of conventional electrical power generation, alternative technologies such as renewable and clean energy resources in generating electricity are necessary. Thermoelectric technology is one of the technologies which can directly convert clean energy resources into electricity, in which heat is directly converted into electricity. In this work, the authors have theoretically simulated the power output of TEG based on potential oxide semiconductors $\left(\mathrm{ZnO}, \mathrm{TiO}_{2}\right.$ and $\left.\mathrm{CuO}\right)$ as thermoelectric materials combined with electrode materials $(\mathrm{Au}, \mathrm{Ag}, \mathrm{Cu}$, graphene, graphite, ITO, IZO and AZO) to clarify the effect of material combination on its power output. The authors evaluated the power output by considering the simulated heat distribution and output voltage of single leg and thermopile using a simulator. The authors determined that the combination of $\mathrm{ZnO}$ and graphene as a single leg of thermopile exhibits the highest power output. This result was likely due to the high thermal conductivity of the graphene, which allows high temperature difference in ZnO. Moreover, the power output was also observed to increase with decreasing the thickness of the electrode, which allows high output voltage to be generated by the thermoelectric material. The power density of TEG containing several thermopiles based on $\mathrm{ZnO}$ and graphene was $29 \mathrm{~mW} / \mathrm{cm}^{2}$, which was comparable to Te based materials.

The third paper written by L. Jacques, D. Steve, and H. Alain reviews the topic of cast irons. In this article, the authors reviewed the subject from many perspectives, with an emphasis on environmentally friendly materials worthy of continuous research. The authors reviewed the uniqueness of cast iron, which is among the metallic materials which have a wide diversity of variants, properties, and applications. The authors argued that no other material can claim to have such a complexity. Citing references in the field, the authors indicated to what extent human knowledge has become able to control the properties of cast irons. This knowledge has enabled a material with a unique combination of design flexibility, mechanical properties, wear resistance, recyclability, low life cycle energy consumption, and low cost.

The fourth paper written by C.I. Lamandasa, A. Setiawan, S. Harjanto, and M.A. Rhamdhani presents the effect of palm kernel shell addition on phase transformation and microstructure of ilmenite during carbothermic reduction. In this research paper, the authors indicated that published reports on the use of biomass as a reducing agent in the upgrading process of ilmenite are still limited. Therefore, the authors utilized palm kernel as an alternative carbon source in carbothermic reduction process of ilmenite. In their work, the ilmenite concentrate was reduced at a temperature range of $1000-1200^{\circ} \mathrm{C}$ for up 
to 3 hours in an inert atmosphere. The amount of reducing agents was varied between 6 and $10 \mathrm{wt} . \%$. The reduced samples were studied using X-ray diffraction and an optical microscope to analyze their phase transformation and microstructure. The results revealed that near-complete dissociation of ilmenite was attained when biomass addition was up to 8 wt.\%. Complete dissociation of ilmenite occurred and $\mathrm{Ti}_{3} \mathrm{O}_{5}$ formed when ilmenite was reduced with 9 wt.\% biomass at $1200^{\circ} \mathrm{C}$ for 2 hours. At this point, the microstructure exhibited the formation of a significant amount of metallic iron with an average size of 241.5 $\mu \mathrm{m}^{2}$.

The fifth paper written by M.S. Anwar, R.K. Melinia, M.G. Pradisti, and E.S. Siradj discusses the effect of prior austenite grain-size on the annealing twin density and hardness of austenitic stainless steel. In this article, the authors studied two types of austenitic stainless steel (i.e., the $253 \mathrm{MA}$ and 316L). These two austenitic stainless-steel types were subjected to multi-pass cold rolling to reduce thickness up to $2.3 \mathrm{~mm}$. Subsequently, the rolled steels were heat treated at $1100^{\circ} \mathrm{C}$ at $0,900,1800,2700$ and 3600 seconds in a tubular furnace under a hydrogen atmosphere. At the end of the annealing time, the rolled steel was quenched in the cooled zone of the tubular furnace until it reached room temperature. Microstructure observation was performed to observe the austenitic grainsize and annealing twin, and the hardness was observed using Vickers microhardness. The results demonstrated that austenite grains of both steels grow normally; 253 MA has a lower SFE and K value than that of 316L, which indicated that $253 \mathrm{MA}$ has sluggish grain growth, smaller grain, easily formed annealing twins, and higher twin density. The HallPetch coefficient, K', of 253 MA has a higher value than that of 316L, which resulted in a high hardness value. The Sellar, Pande and Hall-Petch models can predict austenite grain size, twin density, and hardness in $253 \mathrm{MA}$ and 316L, respectively.

In the sixth paper, A. Aziz, M. Yang, T. Shimizu, and T. Furushima examine the effect of grain misorientation and martensitic transformation on surface roughening behavior of thin austenitic stainless-steel foils. Thin foil stainless steels have unlimited applications in the field of micro-forming industries that make them attractive for use in industrial society. The problem is that thick and ultra-thin metals have different mechanical properties with the same plastic deformation characteristics. In this article, the authors compared the martensitic phase transformation (MPT) effect in SUS 304 and SUS 316, which was clarified in the samples that were of the same grain size (Dg). The correlation between the MPT, grain misorientation (GM), and surface roughening behavior of SUS 304 and 316 thin metal foils was investigated using a uniaxial tensile test in quintet, with constant strain increments of $1.5 \%$. Phase transformations such as the MPT and GM were investigated using scanning electron microscopy/electron backscattered diffraction (SEM-EBSD). The results demonstrated that surface roughening increased proportionally in both the SUS 304 and SUS 316 thin foils with a coarse grain size (Dg of $9.0 \mu \mathrm{m})$. Surface roughening increased to a greater extent in the coarse-grained SUS 304 and 316 thin metal foils compared to in the fine-grained (Dg $1.5 \mu \mathrm{m})$ samples. The SEM-EBSD results demonstrated that the grain strength of the coarse-grained SUS 316 thin metal foil was less inhomogeneous than that of the coarse-grained SUS 304 thin metal foil. The surface roughness ratio of the coarsegrained SUS 304 was higher than that of the coarse-grained SUS 316.

The seventh paper was written by Zulkarnain and T. Arvianti. In this article, the authors analyzed the implicit value of property characteristics in residential property prices using a hedonic value approach. The discussion starts with the fact that the residential property prices are increasing every year without an equivalent increase in people's purchasing power. To suppress these price fluctuations, the authors recommended that the government implement the land banking concept, where quantitative knowledge about 
factors affecting property prices could optimize the implementation. The authors also identify the implicit value and influence of public facilities and landscapes located around residential properties. In their work, the authors identified implicit value through a hedonic value approach which is used to estimate the value of residential properties associated with the distance to public facilities and landscapes. Multiple linear regression (MLR), quantile regression (QR), and support vector regression (SVR) were used to analyze the data. It was found that MLR provided the best accuracy $\left(R^{2}=0.798\right)$, followed by $Q R\left(R^{2}=0.687\right)$, and SVR $\left(\mathrm{R}^{2}=0.563\right)$. It is also observed that the proximity of residential properties to MRT stations, green open spaces, reservoir lakes, health service facilities, vocational schools, marketplaces, high schools, and mosques have significant influences on residential property prices. In addition, MRT stations, health service facilities, marketplaces, and high schools have the largest implicit value consecutively.

The eight paper was written by A.L. Sambowo and A. Hidayatno. In this research article, the authors present the resilience index development for the manufacturing industry based on robustness, resourcefulness, redundancy, and rapidity. The article is an important contribution because the manufacturing industry has always been one of the most significant GDP contributors globally, approximately 15\% of global GDP. The authors claim that due to unknown future challenges, the industry must begin to consider and improve their underlying resilience capabilities to survive. In this article, the authors offer a fundamental resilience index that can be applied to different manufacturing industries to guide them in developing a strategy to increase their resiliency. The authors described that resilience has four main factors, namely robustness, resourcefulness, redundancy, and rapidity. The authors combined these four factors with the four typical organizational functions in operations, financial, strategy, and human resources. Each resilience factor has a set of indicators obtained through literature studies and in-depth interviews with experts. The authors propose that the most influential factors and resilience indicators would be redundancy and reserve funds, respectively. Furthermore, the authors found that reserve funds, customer satisfaction, and demand forecasts are indicators that rank in the top three in terms of the highest weighted value.

The ninth paper written by R.W. Nurhayati, D.S.H. Lubis, G. Pratama, E. Agustina, Z. Khoiriyah, K. Alawiyah, and J.A. Pawitan discusses a topic in the field of stem cell research. In this article, the authors present the effects of static and dynamic culture systems on cell proliferation and conditioned media of umbilical cord-derived mesenchymal stem cells. The discussion starts with preclinical and clinical studies that shows that the therapeutic effects of umbilical cord-derived mesenchymal stem cells (UC-MSCs) and secretome could cure various degenerative diseases. Because of this, the authors argue, mass scale production of MSCs is necessary to ensure their availability and cost-effectiveness. In their work, the authors evaluated the effect of dynamic 3D and static 2D culture systems for cell proliferation and conditioned media of UC-MSCs. The authors used the lysate of concentrated thrombocyte to substitute animal-derived serum in the culture media. Based on 2 experimental sets with different UC and lysates of concentrated thrombocyte donors, they found that the shortest PDTs for experimental set 1 were $12.3 \mathrm{~h}$ (2D culture) and 14.8 $\mathrm{h}$ (3D culture) whereas in experimental set 2 were $17.7 \mathrm{~h}$ (2D culture) and $16.9 \mathrm{~h}$ (3D culture). Their microscopic observations also confirmed the formation of cell aggregates in the 3D system, particularly during the exponential phase. SDS-PAGE analysis revealed similar protein profiles of conditioned media from both culture systems. An antiinflammatory cytokine, tumor necrosis factor beta (TGF- $\beta$ ), was analyzed using ELISA to evaluate the effect of culturing method on TGF- $\beta$ release. The authors also observed the significant fact that the relative TGF- $\beta$ contents in $2 \mathrm{D}$ culture were stagnant throughout the 
incubation times, whereas the higher accumulation of TGF- $\beta$ were detected in 3D culture, which was probably caused by shear stress. The authors confirmed that the dynamic culture system with microcarrier-supported bioreactor is a promising approach to scale up MSC and secretome production.

The tenth paper was written by A. Febriasari, M. Suhartini, A.L. Yunus, Rahmawati, Sudirman, B. Hotimah, R.F. Hermana, S. Kartohardjono, A. Fahira, and I.P. Permatasari. In this article, the authors present research results from gamma irradiation of cellulose acetate-polyethylene glycol 400 composite membrane and its performance test for gas separation. The authors present this topic since gas separation processes through membrane permeation have promising applications and have attracted the attention of many investigators. In this work, the authors modified the cellulose acetate (CA) membrane to improve membrane performance for $\mathrm{CO}_{2} / \mathrm{CH}_{4}$ gas separation. The $\mathrm{CA}$ membrane was modified by adding polyethylene glycol (PEG) 400 as the carrier and N-N'-methylene bisacrylamide (MBA) as the cross-linking agent. The authors used gamma-ray from cobalt 60 as a reaction initiator with the variation of irradiation dose. The researchers analyzed the membrane using scanning electron micrograph (SEM), Fourier transforms infrared (FTIR), and tensile strength. The permeability and selectivity of the membranes were tested against single gases $\mathrm{CO}_{2}$ and $\mathrm{CH}_{4}$. The authors used SEM analysis to present the morphological change of the membrane surface by gamma irradiation and a crosslinking agent. The spectra of FTIR exhibited a change in peak intensity on several polymer functional groups in the presence of gamma-ray irradiation. The tensile strength test demonstrated that membranes with MBA have higher mechanical strength than those with no MBA. Based on membrane permeability and selectivity tests, the $\mathrm{CO}_{2}$ gas permeability was found to be affected by the pressure. The authors also identified that the ideal selectivity of $\mathrm{CO}_{2} / \mathrm{CH}_{4}$ is that the irradiated membrane has a higher selectivity than that of the non-irradiated membrane.

The eleventh paper written by K. Lischer, F. Avila, M. Sahlan, and Y. Whulanza presents an assessment of cost-efficient thermocycler prototype for polymerase chain reaction and loop-mediated isothermal amplification. The authors indicated that DNA amplificationbased diagnostic is one of the most accurate methods. Since the instrumentation and amplification reagents still depend on the imported products while local demand is increasing, an effort for the domestic production is essential. In this article, the authors have constructed a cost-efficient thermocycler prototype using Raspberry Pi and Phyton coding. The authors compared thermocycler prototypes and commercial for two types of DNA amplification reactions, polymerase chain reaction (PCR) and loop-mediated isothermal amplification (LAMP). PCR is a more common method than LAMP, with the main difference being PCR requires thermal cycling and LAMP operates in isothermal conditions. LAMP has a quicker reaction time and operates at a lower temperature. DNA pol with high strand displacement activity is used for LAMP. In their work, Bsm pol was used for LAMP and Taq pol was used for PCR. Since the prototype thermocycler is designed to be as simple and inexpensive as possible for ease of manufacture and accessibility for every layer of society, its heat control and stability would not be as good as a commercial thermocycler. This results in prototype incapability of performing PCR, and no DNA band at 250-500 bp range in gel electrophoresis. However, the prototype is capable of performing LAMP, existing $<100 \mathrm{bp}$ DNA gradient band in gel electrophoresis. The prototype is also capable of performing LAMP below its protocol temperature and time separately, $62^{\circ} \mathrm{C}$ and 40 minutes compared to the protocol of $66^{\circ} \mathrm{C}$ and 60 minutes.

The twelfth paper was written by F.N. Hakim, Y. Muhamadinah, Atthaillah, R.A. Mangkuto, and A.S. Sudarsono. In this research article, the authors discuss building an 
envelope design optimization of a hypothetical classroom by considering energy consumption, daylighting, and thermal comfort. In their work, the authors presented their case study results in Lhokseumawe, Aceh, Indonesia. Variations in building materials, constructions, and horizontal shading features were evaluated for the most optimum design solution, aiming at optimizing the multi-performance criteria as an integrated sustainable design solution for a typical classroom in Indonesia. To achieve the objective, the authors utilized a computational simulation method using Rhinoceros, Grasshopper, and Ladybug Tools platforms. The optimization was conducted using Galapagos, an engine based on a genetic algorithm. The results revealed that the optimum solution achieved $100 \%$ sDA300/50\% and more than 96\% UDI100-3000lx. The annual thermal comfort percentage was also improved by more than $90 \%$, while the energy consumption was reduced by $20 \%$ compared to the baseline design.

The thirteenth paper written by K.D. Paramita, A. Karimah, and Y.A. Yatmo discusses collective strategies and spatiality of neighborhood food co-production during the COVID19 pandemic. In the article, the authors explored the strategies and spatiality of neighborhood food co-production during the second wave of the COVID-19 pandemic in Indonesia. The authors argued that since the COVID-19 pandemic creates global food instability, collective strategies to transform food and the source of food for people in need are necessary. This article is particularly focused on neighborhood-driven co-production of food for the rising rate of home-isolated COVID-19 patients, which generates new spatial programming and interconnection between dwellings, neighborhoods, and the city. In their work, the authors utilized Twitter data to examine such issues, harnessing 141,208 tweets related to COVID-19 and neighborhoods in Indonesia, which were then filtered into 128 food-related tweets, analyzed through categorical and networked revelation analysis. The analysis demonstrates strategies of food co-production from sourcing food ingredients, managing daily food transformation, or creating centralized structures, while the spatiality of food co-production highlights the neighborhood accessibility, food placement structures, and dwelling configurations. The food co-production strategies exist as a dynamic and responsive approach towards the fluctuating condition of neighborhood dwellers, shaping the spatiality of the neighborhood and heightening their resilience.

The fourteenth paper was written by T. Tjahjono, A. Kusuma, M. Adhitya, R.Y. Purnomo, T. Azzahra, A.J. Purwanto, and G. Mauramdha. In this article, the authors present public perception of pricing towards vehicle biofuel policy in Indonesia. The authors argued that since Indonesia will implement EURO IV standard emission by the end 2021, Indonesia will also need to eliminate the incentive policy for fossil fuels such as fuel price subsidies. As an alternative, the government provides a new fuel technology, namely biofuel, to improve environmental conditions and increase palm production in Indonesia. In this article, the authors observe the public perception towards the pricing policy at the time biofuel was introduced. The authors applied the discrete choice model through a stated preference survey. The authors found that most people would shift to biofuel, particularly green diesel, although the price would be higher than the current fuel due to its molecular structure being similar to petroleum diesel but provides better diesel properties. The authors indicated that the condition only applies, however, if there is no other alternative and it is mandatory to implement EURO IV standard emissions. In the end, to accommodate the potential demand, the supply side such as car manufacturers need to fulfil the number of vehicles as it is predicted that the demand will continue to increase.

The fifteenth paper was written by I.J. Maknun and S. Zarfatina. In this article, the authors discuss a topic on shear correction factor effects on functionally graded materials (FGMs) beam using discrete shear gap (DSG) element. The authors claimed that materials 
and computational methods are essential to support the development of infrastructure. One of the materials currently with potential for use in infrastructure is composite material, which has been used in many applications. In the laminated composite, however, the failure could be due to excessive interlaminar stresses between two materials that causes delamination. One of the ways to solve this problem is by using functionally graded materials (FGMs). A numerical computation such as the finite element method (FEM) is widely used to support the analysis of FGMs in structural applications. DSG element was developed using Timoshenko beam theory, where the shear correction factor is used in their formulation. The shear correction factor is assumed to be constant in many applications. This is valid for isotropic homogenous materials; however, the effect of shear deformation significantly impacts the results of the FGMs beam, so the shear correction factor cannot be constant. Therefore, the authors present the shear correction factor effect on static analysis of FGMs beam using DSG element. Various boundary conditions with length thickness ratio $(\mathrm{L} / \mathrm{h}=4)$ were evaluated. The DSG element yielded good results in FGMs beam for different power-law index ratios. The authors also found that the higher the modulus of elasticity ratio of the top-to-bottom material, the further the difference between $\mathrm{k}$ FGMs and $\mathrm{k}=5 / 6$ (constant). The DSG element can provide precise results without shear locking.

The sixteenth paper written by H. Purnomo, H. Baskoro, and F. Muslim presents a topic on stress and strain behavior of confined lightweight concrete using sand coated polypropylene coarse aggregate. The authors claimed that since plastic waste greatly contributes to environmental pollution, it is therefore important that plastic waste should be used in various applications such as in concrete. The authors present the development of concrete stress and strain model under compression of unconfined and confined concrete specimens using polypropylene plastic as a substitution for coarse aggregate. Various short column specimens were analyzed, including stress and strain characteristics, effect of steel confinement, and compressive performance. The results demonstrate that steel confinement increases compressive strength and ductility of the section. The authors used the parametric identification of stress-strain model defined for normal concrete to obtain the new parameter values for the confinement coefficients $\mathrm{k}_{1}$ and $\mathrm{k}_{2}$ that are suitable for a lightweight concrete. The stress-strain diagram for lightweight concrete of cylinder and square column specimen compared with the stress-strain modeled by modified coefficients indicated a close agreement.

The seventeenth paper written by A. Lololau, T.P. Soemardi, H. Purnama, and O. Polit discusses a topic on composite multiaxial mechanics. In their article, the authors investigate laminate design optimization of taper-less wind turbine blades with ramie fiber reinforced polylactic acid. The authors claimed that since the research on composite based on natural resources is proliferating, ramie fiber and polylactic-acid (PLA) would be fully biodegradable composite materials for mechanical applications due to their excellent strength and degradability. In this article, the authors aimed to theoretically optimize the fully biodegradable ramie/PLA laminate design by its lamina orientation on a taper-less blade shell of a wind turbine. This would be significant since the structure experienced multiaxial loading through bending and torsional moment. The selection of taper-less blades was due to their congruence with the wind speed categorization in southeastern Indonesian territory. The authors carried out optimization using the nonlinear generalized reduced gradient (GRG) method on Microsoft Excel. The optimized laminate result is in a stacking sequence of $\left[-4^{\circ}, 24^{\circ}, 47^{\circ}, 65^{\circ}, 74^{\circ}, 79^{\circ}\right] \mathrm{S}$ that delivers the factor of safety, which is the ratio between the allowable stress to the actual stress, of 7.296 and 18.057 on the 
longitudinal axis and the laminate plane, respectively, which makes the composite laminate safe, both theoretically and numerically.

The eighteenth paper was written by L.P. Wibisana and M.A. Budiyanto. In this article, the authors present a topic on the design and cost of multi-objective optimization of smallscale liquified natural gas (LNG) carrier combined with value engineering approach. The authors indicated that LNG carrier is the main merchant fleet to transport natural gas for energy supply. The large LNG carrier has a more efficient freight cost (approximately 7.8 USD/MMBTU) relative to a small-scale LNG carrier freight cost (approx. 12.8 USD/MMBTU), which is less cost-effective than a larger-scale LNG carrier. Because of this, the authors suggested another approach to gain efficiency in small-scale LNG carriers (SSLNGC). In their work, the authors expedite a sample case to improve the design of SSLNG by design and cost optimization by combining value engineering approach and multiobjective optimization to gain less hull resistance and lower construction material cost by adjusting ship dimension ratio. By improving the conceptual design and semi-integrated numerical simulation, the result could facilitate improvement by decreasing hull shell area by $1.57 \%$ to reduce construction material and reduce total ship resistance by $8.3 \%$.

The nineteenth paper written by P. Rupajati, K.G. Clarissa, A.S. Baskoro, G. Kiswanto, and Winarto presents a topic on micro-friction stir spot welding of AA1100 and brass. In this research article, the authors discuss the characteristics of mechanical properties and microstructure of micro-friction stir spot welding (mFSSW) of AA1100 and brass. Friction stir spot welding is a solid-state welding widely developed using both similar materials and dissimilar materials. Aluminum AA1100 (99\% Al) and brass (Cu-Zn) with a thickness of $0.42 \mathrm{~mm}$ were used. The authors examined the characteristics of the lap shear force and microstructure of micro friction stir spot welding joint on similar aluminum alloy AA1100, similar brass, and dissimilar AA1100-brass materials using pin tool made of high-speed steel. The constant process parameters of the mFSSW joint of plunge depth, dwell time, plunge rate, and high tool rotational speed was $0.7 \mathrm{~mm}, 6 \mathrm{~s}, 4 \mathrm{~mm} / \mathrm{min}$, and 33,000 rpm, respectively. Similar materials exhibited a higher lap shear force than that of dissimilar materials. The number of spots on the similar AA100 had no significant effect on the lap shear force, while with similar brass, the number of spots had a significant effect on lapshear force. The formation of a very thin intermetallic compound layer in the nugget zone occurred in the dissimilar material. The authors also found that the lap shear on the similar material AA1100 and similar brass has a lap shear force with a plug fracture type, while the type of fracture found in dissimilar materials was the interface failure mode.

The twentieth paper written by J. Triwardono, S. Supriadi, Y. Whulanza, A.S. Saragih, D.A. Novalianita, M.S. Utomo, and I. Kartika discusses a topic on contact area evaluation of redesigned total knee arthroplasty for deep knee flexion. Total knee arthroplasty (TKA) implants are still an emerging topic in the implant design research and development activities due to its complexity. In practice, it should be able to facilitate the nature of knee movement while supporting body weight in daily usage. Incidents such as hyperflexion in TKA implant outside their designated configuration can lead to subluxations and dislocations. The authors have developed polyethylene component of posterior-stabilized right knee joint implant to facilitate higher range of motion (ROM). In their work, the authors used finite element analysis (FEA) to simulate and analyze contact area on the polyethylene component. The weight-bearing conditions were at $0^{\circ}, 30^{\circ}, 60^{\circ}, 90^{\circ}, 120^{\circ}$ and $150^{\circ}$ of knee flexion. The results revealed that modified polyethylene component gives better performance in terms of contact area, especially at $120^{\circ}$ of knee flexion. Two dominant contact areas were $733 \mathrm{~mm}^{2}$ at $0^{\circ}$ of knee flexion and $576 \mathrm{~mm}^{2}$ at $120^{\circ}$ of knee flexion. The current design is capable of maintaining the existence of contact area at $150^{\circ}$ 
of knee flexion with a contact area of $65 \mathrm{~mm}^{2}$. With this finding, the authors claimed that the current polyethylene component design will accommodate deep knee flexion movement in daily activities and reduce possibility of subluxation and dislocation at polyethylene component during deep knee flexion. A large contact area can reduce potential of wear or fracture of the polyethylene component.

In conclusion, we hope that this special edition of IJTech will provide useful information and knowledge to all readers worldwide and be of benefit to the environment and global ecology.

With warmest regards from Jakarta,

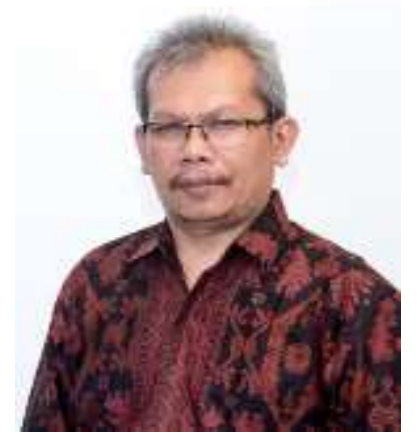

Dr. Nofrijon Sofyan Editorial Board Member

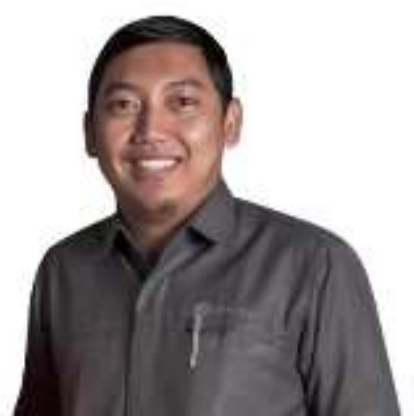

Dr. Muhammad Arif Budiyanto Editorial Board Member

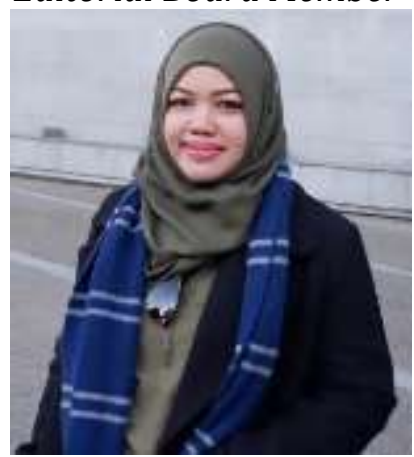

Eny Kusrini, Ph.D. Editorial Board Member

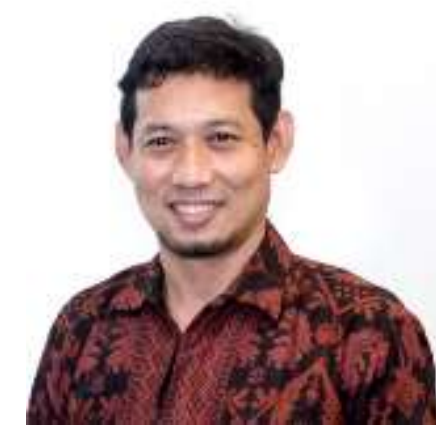

Prof. Akhmad Herman Yuwono Editorial Board Member

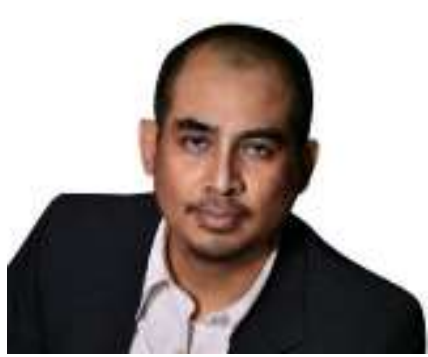

Dr. Yudan Whulanza Editorial Board Member

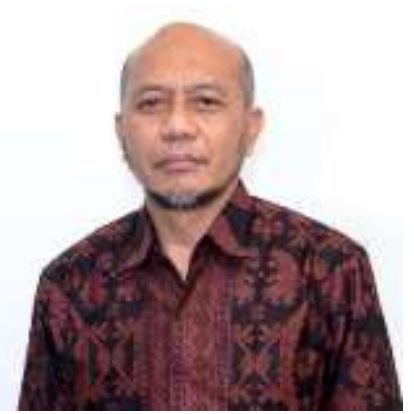

Prof. Ir. Sutrasno Kartohardjono Editorial Board Member

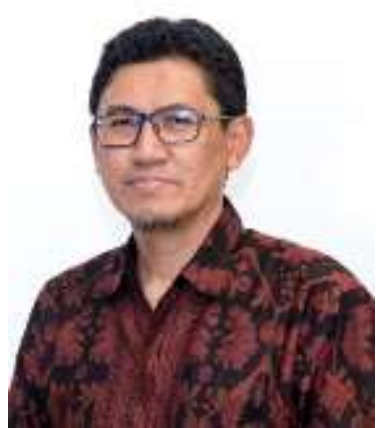

Prof. Sri Harjanto Editorial Board Member

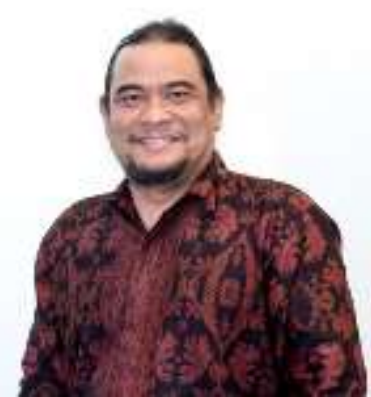

Prof. Nandy Putra Editorial Board Member

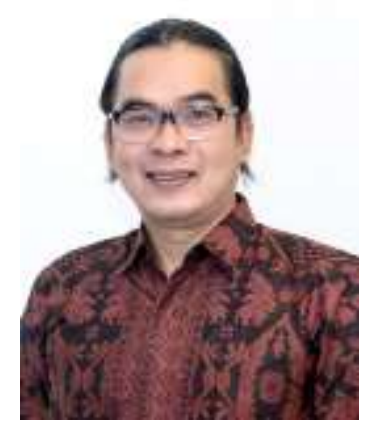

Dr. Mohammed Ali Berawi Editor in Chief 


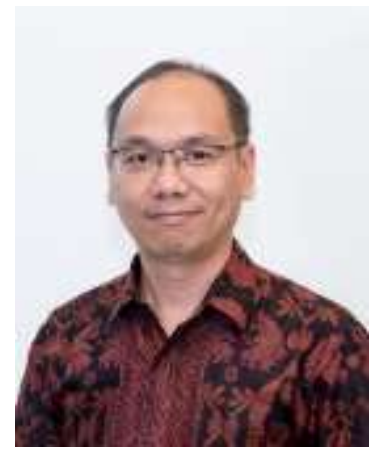

Dr. Nyoman Suwartha Managing Editor

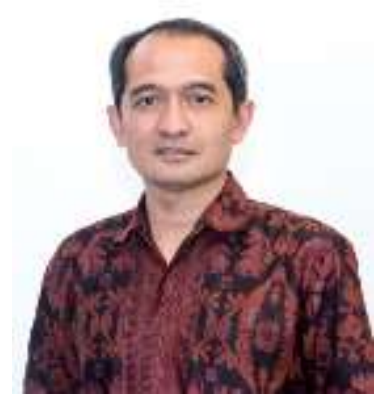

Prof. Yandi Andri Yatmo Editorial Board Member

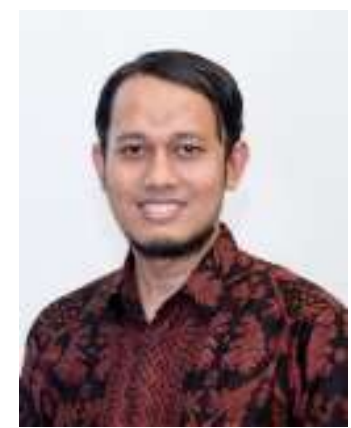

Dr. Muhammad Suryanegara Editorial Board Member

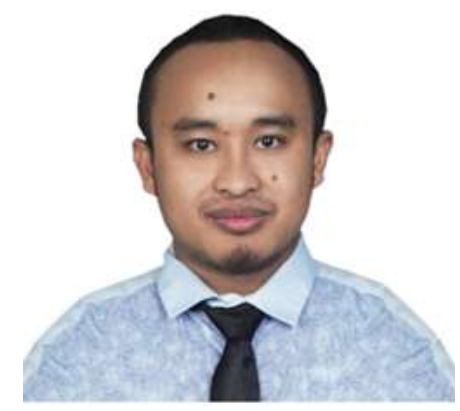

Dr. Imam Jauhari Maknun Editorial Board Member

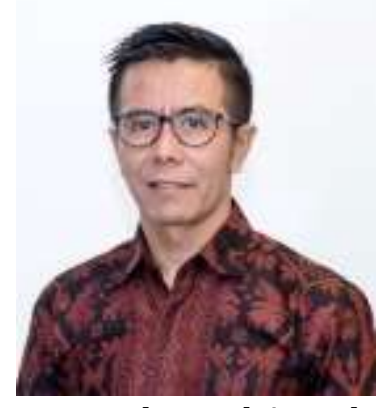

Dr. Muhamad Asvial Editorial Board Member

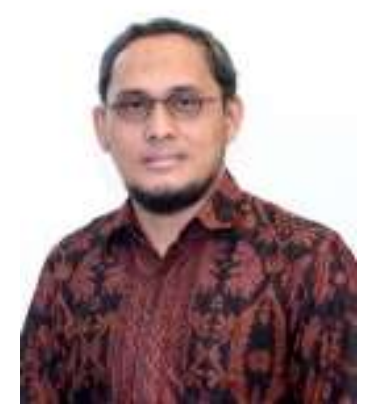

Dr. Eko Adhi Setiawan Editorial Board Member

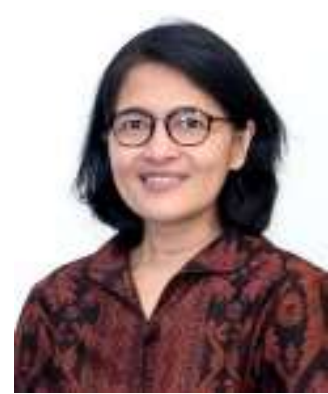

Prof. Isti Surjandari Editorial Board Member

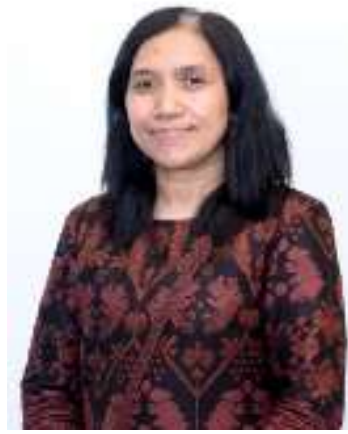

Prof. Paramita Atmodiwirjo Editorial Board Member

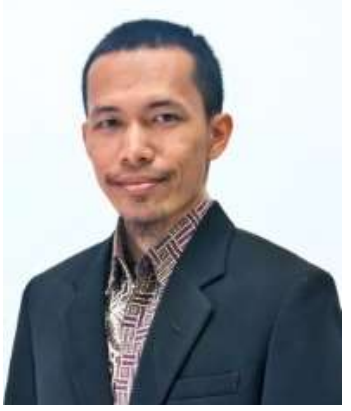

Dr. Ruki Harwahyu Editorial Board Member

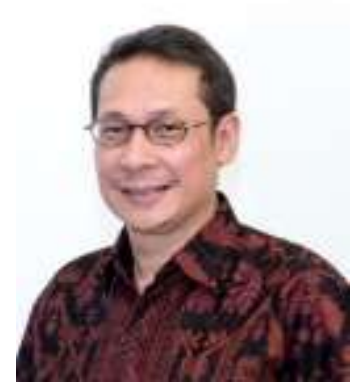

Prof. Teuku Yuri M. Zagloel Editorial Board Member 